\title{
Reconstruction of thumb defects with medial sural artery perforator flap: case series
}

\author{
Xin Huang, Jihua Xu, Hu Yang, Haifei Shi \\ Department of Orthopedics, The First Affiliated Hospital, Zhejiang University School of Medicine, Hangzhou, China \\ Contributions: (I) Conception and design: X Huang, J Xu; (II) Administrative support: H Shi; (III) Provision of study materials or patients: X Huang, J \\ Xu, H Shi; (IV) Collection and assembly of data: H Yang; (V) Data analysis and interpretation: X Huang; (VI) Manuscript writing: All authors; (VII) \\ Final approval of manuscript: All authors. \\ Correspondence to: Haifei Shi. Department of Orthopedics, The First Affiliated Hospital, Zhejiang University School of Medicine, Hangzhou 310003, \\ China. Email: shihaifei@zju.edu.cn.
}

Background: Digital defect is one of the most common types of emergency hand injuries. Plastic surgeons continue to search for a better method to repair digital defects, especially those of the thumb. The medial sural artery perforator (MSAP) flap has been widely used as a popular method for limb and head reconstruction. Our findings have led us to advocate the use of free medial sural artery perforator flap to repair large thumb defects.

Methods: From July 2010 to July 2013, we used free MSAP flaps to resurface large defects of 9 thumbs in 9 clinical cases. There were 6 men and 3 women among the participants, aged 21-49 years (average age: 37.6 years). Flap sizes varied from $2 \mathrm{~cm} \times 3 \mathrm{~cm}$ to $3 \mathrm{~cm} \times 6 \mathrm{~cm}$. Perforators of all flaps were accurately located by color Doppler detection.

Results: According to color Doppler detection, the distance from the popliteal crease to the points where first/second perforator pierced the deep fascia was $10.1 \pm 1.1 / 15.2 \pm 0.8 \mathrm{~cm}$. The distance from the midline to the first/second perforator was $2.8 \pm 0.8 / 3.5 \pm 0.5 \mathrm{~cm}$. A total of nine flaps fully survived. All defects of the nine thumbs were adequately resurfaced. Postoperative follow-up conducted at 12-24 months revealed satisfaction in both cosmetic and function results.

Conclusions: The MSAP flap, which can be easily harvested and well thinned, is an ideal choice to repair thumb defects. Accurate location of the perforator by Doppler detection ensures the surgical success, and minimizes injury to the donor site.

Keywords: Perforator flap; thumb defects; medial sural artery; color Doppler

Submitted Dec 30, 2020. Accepted for publication Apr 22, 2021.

doi: $10.21037 / \mathrm{atm}-21-526$

View this article at: http://dx.doi.org/10.21037/atm-21-526

\section{Introduction}

Digital defect is one of the most common types of emergency hand injuries. When the defects are too large to be reconstructed by local flaps, there is a preference to use free flaps. Lai et al. (1) suggested using free tissue transfer to repair a distal third or distal half of thumb defects to create a sensate and durable resurfacing. To decrease damage to the donor site, various free perforator flaps have been widely initiated to repair digital defects in recent years (2-6).
The common disadvantage of these methods, which may cause both function and cosmetic problems, is that the donor sites of these flaps locate in the upper extremities.

The medial sural artery perforator (MSAP) flap has been widely used as a popular method for limb and head reconstruction, the donor site of which lies in medial calf (7-17). The advantages of this method include minimal destruction of function, less morbidity, primary closure without skin graft of donor site, and a discreet scar leading to satisfactory contours. 


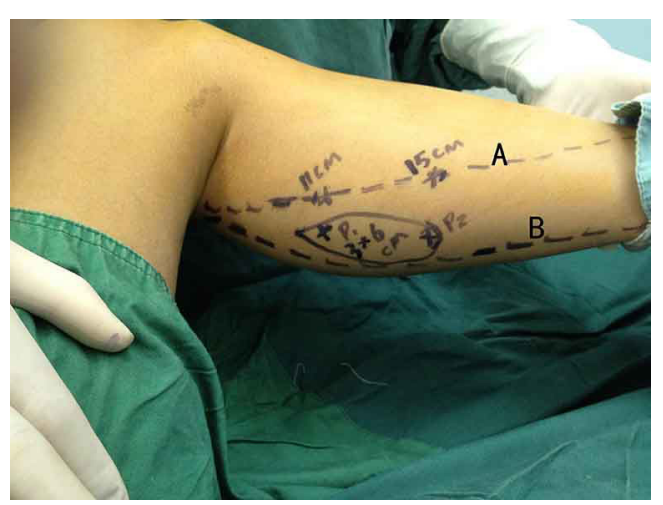

Figure 1 Position and marking for the MSAP flap. Line A: drawn from the midpoint of the popliteal crease to the midpoint of the medial malleolus. Line B: the posterior midline drawn from the midpoint of the popliteal crease to the Achilles tendon. MSAP, medial sural artery perforator.

The medial sural artery originates from the popliteal vessels, descends inside the medial gastrocnemius muscle, and runs along an imaginary line connecting the midpoint of the popliteal crease and that of the medial malleolus. Numerous muscular nutrition arteries branch from the medial sural artery along its course. There are usually two important fasciocutaneous perforators that are suitable as pedicles of free flaps to be found. The average distance from the midpoint of the popliteal crease to the first and second perforators is about 10 and $16 \mathrm{~cm}$, respectively. The average diameter of the arteries is about $1-2 \mathrm{~mm}$, and the diameter of the accompanying veins adequate for venous drainage in the MSAP flap is even larger $(7,9,11)$.

Currently, we are unaware of any documentation of the clinical application of MSAP for reconstruction of digital defects. Therefore, we composed this article to share the technique of perforator detection using color Doppler, and our experience with reconstruction of digital defects using the MSAP free flap in 9 cases.

We present the following article in accordance with the AME Case Series reporting checklist (available at http:// dx.doi.org/10.21037/atm-21-526).

\section{Methods}

Between July 2010 and July 2013, 9 patients with 9 MSAP free flaps were treated for reconstruction of large thumb defects. There were 6 men and 3 women among the participants, aged 21-49 years (average age: 37.6 years). The size of the wound with deep tissue exposure caused by heavy weight extrusion and sharp instrument cutting varied from $2 \mathrm{~cm} \times 3 \mathrm{~cm}$ to $3 \mathrm{~cm} \times 6 \mathrm{~cm}$.

The participant was placed in a supine position, with the donor leg flexed into a $90^{\circ}$ angle and externally rotated. Line A was drawn from the midpoint of the popliteal crease to the midpoint of the medial malleolus. Line B was the posterior midline, drawn from the midpoint of the popliteal crease to the Achilles tendon. The points where the perforator pierced fascia were marked between the two lines (Figure 1).

Due to the flap being small, the position of the perforator had to be located accurately. Therefore, color Doppler imaging was used to detect the actual position of the perforator. The detection was conducted between Line A and Line B. The blood signal and waveform of the vessels were observed to confirm the artery, and both perforators were found in all 9 cases using this technique. Surface marks were made at the point where perforators pierced the deep fascia according to the color Doppler imaging (Figure 2). We usually chose the second perforator as the single pedicle of the flap to gain an adequate length of the vascular pedicle.

Thorough debridement and exploration were carried out at the trauma site. Proper branches of the radial artery and cephalic vein were separated in nasopharyngeal fossa.

With a medial incision, the second perforator was explored and then the flap was designed according to position of the perforator, locating the vascular pedicle on the distal side of the flap. The vascular pedicle was completely separated from the surrounding muscle during the course, and then disconnected at the root to gain an adequate length. The whole flap was elevated and totally defatted after the vascular pedicle was separated, and was transferred to the thumb defect location for vascular pedicle anastomosis. The donor site was primarily closed without any skin graft.

All procedures performed in this study involving human participants were in accordance with the Declaration of Helsinki (as revised in 2013). The study was approved by the Ethics Committee of The First Affiliated Hospital, Zhejiang University School of Medicine (No.: 2021-IT175) and informed consent was taken from all the patients.

\section{Results}

According to color Doppler detection, the distance from the popliteal crease to the points where first perforator pierced the deep fascia was $10.1 \pm 1.1 \mathrm{~cm}$, and was $15.2 \pm 0.8 \mathrm{~cm}$ to the points where the second perforator pierced the deep fascia. 

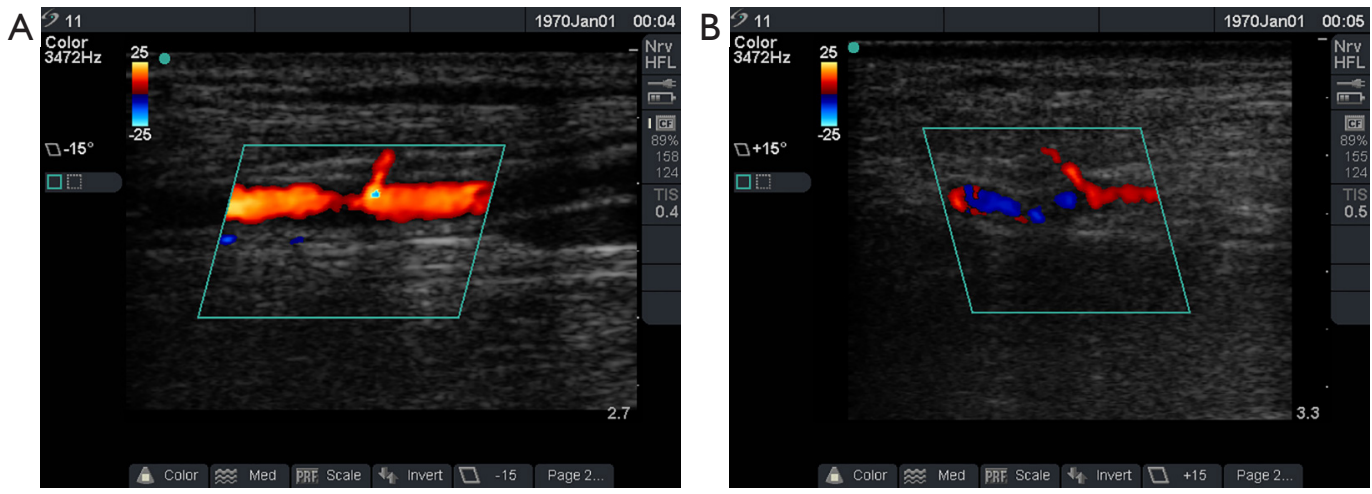

Figure 2 Actual position and flow parameters of the perforator detected by color Doppler. (A) Blood flow spectrum of the perforator artery; (B) blood flow spectrum of the perforator vein.

Table 1 Flap characteristics in participants undergoing MSAP flaps

\begin{tabular}{|c|c|c|c|c|c|c|c|c|}
\hline Gender & Age & $\begin{array}{l}\text { Flap size } \\
\text { (cm) }\end{array}$ & $\begin{array}{c}\text { ML-1st/2nd P } \\
\text { (cm) }\end{array}$ & $\begin{array}{l}\text { PC-1st/2nd P } \\
\text { (cm) }\end{array}$ & $\begin{array}{l}\text { SPV 1st/2nd P } \\
(\mathrm{cm} / \mathrm{s})\end{array}$ & $\mathrm{RI}$ 1st/2nd $\mathrm{P}$ & $\begin{array}{l}\text { Diameter 1st/2nd P } \\
(\mathrm{mm})\end{array}$ & Follow-up $(\mathrm{cm})$ \\
\hline M & 21 & $3 \times 6$ & $4.2 / 2.8$ & $11.2 / 16$ & $7.1 / 8.2$ & $0.56 / 0.62$ & $0.9 / 1.2$ & 18 \\
\hline $\mathrm{F}$ & 42 & $3 \times 4$ & $3.2 / 2$ & $9.0 / 14$ & $9.5 / 8.6$ & $0.42 / 0.54$ & $0.8 / 0.9$ & 24 \\
\hline M & 44 & $2 \times 3$ & $3.8 / 2.2$ & $10 / 15.2$ & $8.2 / 6$ & $0.73 / 0.74$ & $1.0 / 1.2$ & 18 \\
\hline M & 49 & $3 \times 6$ & 4.6/3.2 & $11 / 15.6$ & $12.5 / 17$ & $0.54 / 0.52$ & $0.9 / 1.2$ & 12 \\
\hline M & 38 & $2 \times 4$ & $4.3 / 2.8$ & $10.6 / 15$ & $3.6 / 8.2$ & $0.48 / 0.52$ & $0.8 / 1.0$ & 12 \\
\hline M & 35 & $3 \times 5$ & $4.4 / 2.8$ & $11.2 / 15.2$ & $4.2 / 8.6$ & $0.52 / 0.50$ & $1.0 / 1.2$ & 18 \\
\hline
\end{tabular}

ML-1st/2nd P: distance from the midline to the first/second perforator. PC-1st/2nd. P: distance from the popliteal crease to the first/ second perforator. SPV 1st/2nd P: systolic peak velocity of the first/second perforator artery. RI 1st/2nd P: resistive index of the first/ second perforator artery. Diameter 1st/2nd P: vessel diameter of the first/second perforator artery. MSAP, medial sural artery perforator.

The distance from the midline to the first perforator was $2.8 \pm 0.8 \mathrm{~cm}$, and was $3.5 \pm 0.5 \mathrm{~cm}$ to the second perforator (Table 1). Intraoperative measurements showed that the artery pedicles of the perforator were usually larger than $1.0 \mathrm{~cm}$ in diameter at its origin, and more than $10 \mathrm{~cm}$ in length from the origin to the piercing point. Postoperative follow-up over a period of 12-24 months revealed that all 9 flaps had totally survived with good quality and esthetic contours. The grasp function of the hand was satisfactory. No secondary defat was needed. There were no complaints of distal pain, hyperanaesthesia, or any other abnormal sensation. Scarring on the donor site was not obvious. All participants were satisfied with the therapeutic effects.

\section{Case 1}

A 21-year-old man had his left thumb sharply cut by a slicing machine 4 hours before presentation at our department, resulting in a $6 \mathrm{~cm} \times 3 \mathrm{~cm}$ defect of the finger pulp. Upon ultrasonic examination, the second perforator of the medial sural artery in the left leg was $1.1 \mathrm{~cm}$ in diameter and $10 \mathrm{~cm}$ in length. A $3 \mathrm{~cm} \times 6 \mathrm{~cm}$ MSAP flap was designed according to the perforator. The flap was transferred with a vascular pedicle anastomosis to repair the thumb defect. The donor site was sutured without skin grafting. The 18 month follow-up showed that the flap had survived with a satisfactory contour (Figure 3). 

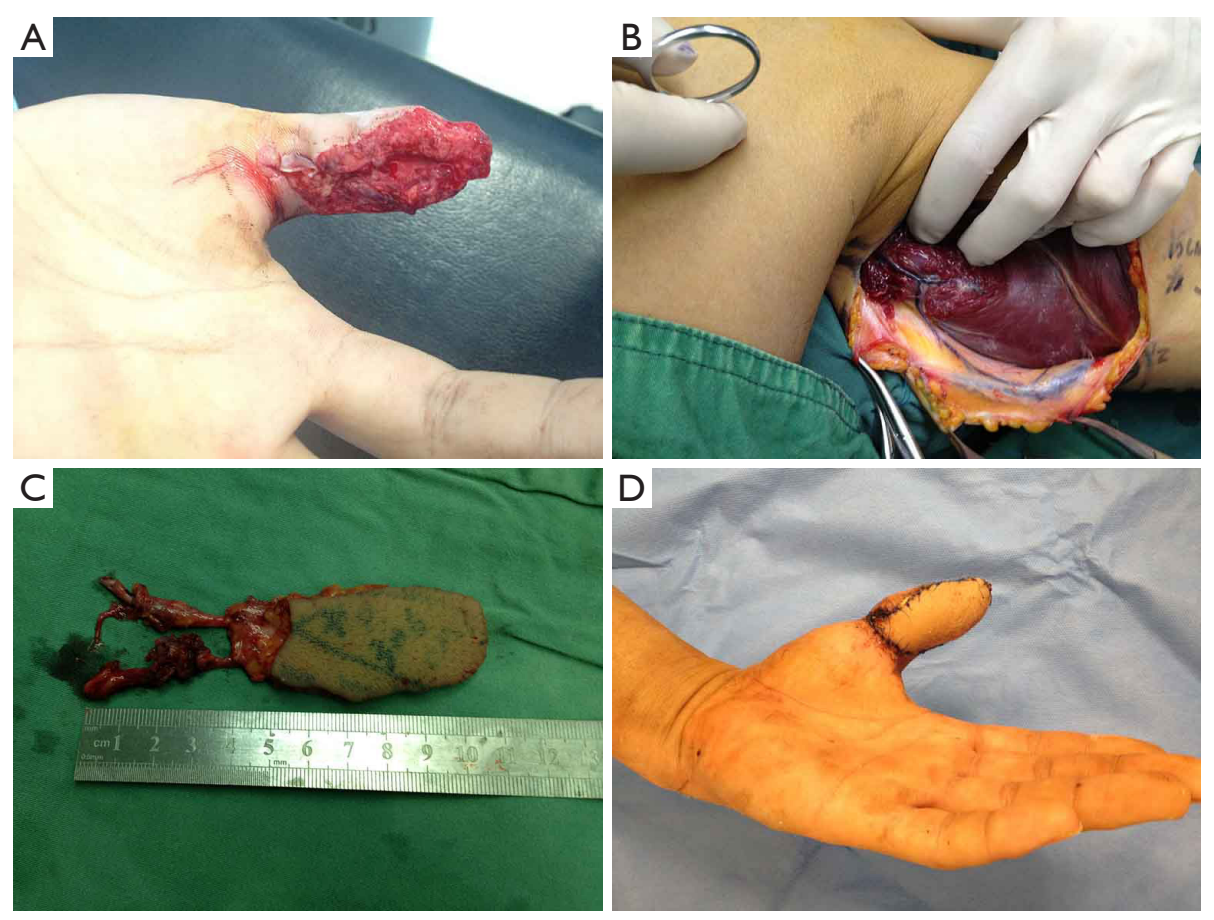

Figure 3 Thumb defect repaired by MSAP flap. (A) Left thumb cut by a machine resulting in a $6 \mathrm{~cm} \times 3 \mathrm{~cm}$ defect of the finger pulp; (B) the second perforator of the medial sural artery in the left leg was $1.1 \mathrm{~cm}$ in diameter and $10 \mathrm{~cm}$ in length; (C) a $3 \mathrm{~cm} \times 6 \mathrm{~cm}$ MSAP flap was designed according to the perforator; (D) appearance of the flap 2 weeks post-operatively. MSAP, medial sural artery perforator.

\section{Case 2}

A 42 -year-old woman had her left thumb extruded by a textile machine 2 hours before presentation at our department, resulting in a soft tissue avulsion in the distal thumb. As her left calf had been previously injured in a traffic accident, we chose the right calf as the donor site. Upon ultrasonic examination, the second perforator of the medial sural artery in the right leg was $1.0 \mathrm{~cm}$ in diameter and $10 \mathrm{~cm}$ in length. A $3 \mathrm{~cm} \times 4 \mathrm{~cm}$ MSAP flap was designed according to the perforator. The flap was transferred with a vascular pedicle anastomosis to repair the thumb defect. The donor site was sutured without skin grafting. The 24-month follow-up showed that the flap had survived with a satisfactory contour (Figure 4).

\section{Discussion}

There are various methods to repair thumb defects such as digital artery island flap, pedicle flap, and free flap. Island flap, which can be considered a local flap, usually causes scar contracture in the hand that sometimes leads to unsatisfactory contour results and serious loss of activity function. Pedicled flap requires immobilization for several weeks which is sometimes harmful to the function of trapeziometacarpal joint. Free flap offers better cosmetic results and less function loss, but it demands an experienced microsurgical technique.

The key to the success of free flap transfer is a successful anastomosis of small vessels. The bigger the diameter of the perforator, the easier the anastomosis will be. Another important factor is the location of the perforator, and an accurate localization is necessary when the flap is rather small.

Recently, fingertip defect reconstruction with various free perforator flaps has been widely reported. The pedicles of free flaps based on perforators of the ulnar or radial artery are usually short in length and small in diameter (3-6), while the MSAP flap provides sizable perforators with sufficient length and diameter $(9,18)$. In our cases, we found that diameter of the perforator artery was usually larger than $1 \mathrm{~cm}$ at the origin of the pedicle, while the diameter of the accompanying vein was even larger. The adequate length of the pedicle accommodates completion of a successful anastomosis far from the wound site.

Accurate localization of the perforator also plays an 

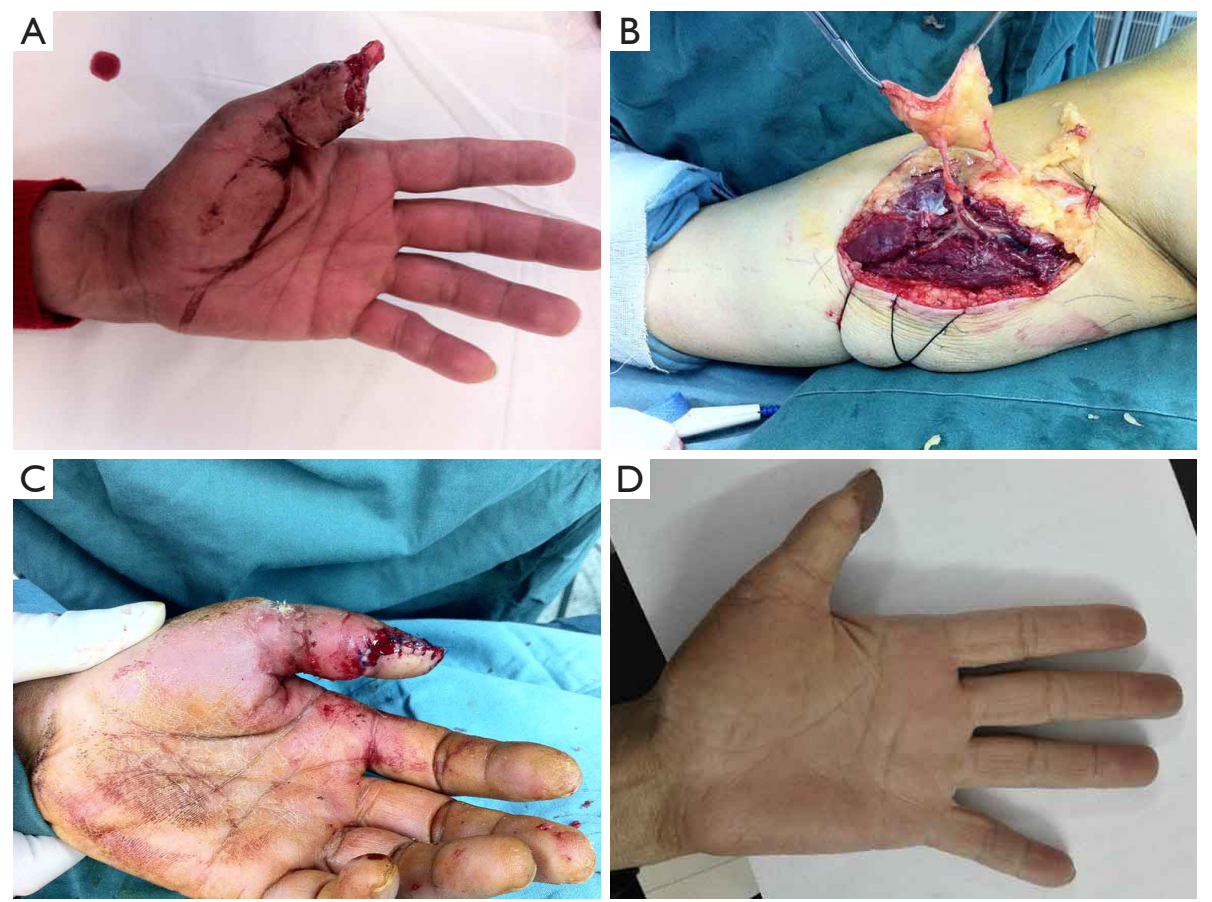

Figure 4 Thumb defect repaired by MSAP flap. (A) left thumb extruded by a textile machine resulting in a soft tissue avulsion in the distal thumb; (B) the second perforator of the medial sural artery in the right leg was $1.0 \mathrm{~cm}$ in diameter and $10 \mathrm{~cm}$ in length; (C) the flap was transferred with a vascular pedicle anastomosis to repair the thumb defect; (D) appearance of the flap 24 months post-operatively. MSAP, medial sural artery perforator.

important role in the course of small flap harvest. Several methods for localizing the perforator have been reported. Kim et al. (11) suggested drawing a line from the midpoint of the popliteal crease to the midpoint of the medial malleolus. The first perforator is located $8 \mathrm{~cm}$ from the midpoint of the popliteal crease within a distal half circle drawn with a 2 -cm radius. Kao et al. (9) recommended plotting the perforators to a coordinate system with $x$ as the distance from the perforator perpendicular to the popliteal crease and $y$ as the distance from the perforator perpendicular to the posterior calf midline.

According to our study, with the assistance of color Doppler, we recommend drawing two lines. Line A was drawn from the midpoint of the popliteal crease to the midpoint of the medial malleolus. Line B was the posterior midline drawn from the midpoint of the popliteal crease to the Achilles tendon. The distance from the piercing point of the perforator to the popliteal crease and to the posterior midline was recorded. We found that all perforators were located between these two lines.

\section{Conclusions}

This study demonstrated that the MSAP flap, which can be easily harvested and well thinned, is an ideal option to repair large thumb defects. Color Doppler detection is a noninvasive method which enables accurate localization of the perforator. Accurate location of the MSAP by color Doppler detection ensures surgical success, and minimizes injury to the donor site.

\section{Acknowledgments}

Funding: This research was supported by Zhejiang Provincial Natural Science Foundation of China under Grant No. LY17H060002.

\section{Footnote}

Reporting Checklist: The authors have completed the AME Case Series reporting checklist. Available at http://dx.doi. org/10.21037/atm-21-526 
Data Sharing Statement: Available at http://dx.doi. org/10.21037/atm-21-526

Conflicts of Interest: All authors have completed the ICMJE uniform disclosure form (available at http://dx.doi. org/10.21037/atm-21-526). The authors have no conflicts of interest to declare.

Ethical Statement: The authors are accountable for all aspects of the work in ensuring that questions related to the accuracy or integrity of any part of the work are appropriately investigated and resolved. All procedures performed in this study involving human participants were in accordance with the Declaration of Helsinki (as revised in 2013). The study was approved by the Ethics Committee of The First Affiliated Hospital, Zhejiang University School of Medicine (No.: 2021-IIT175) and informed consent was taken from all the patients.

Open Access Statement: This is an Open Access article distributed in accordance with the Creative Commons Attribution-NonCommercial-NoDerivs 4.0 International License (CC BY-NC-ND 4.0), which permits the noncommercial replication and distribution of the article with the strict proviso that no changes or edits are made and the original work is properly cited (including links to both the formal publication through the relevant DOI and the license). See: https://creativecommons.org/licenses/by-nc-nd/4.0/.

\section{References}

1. Lai CH, Lai CS, Huang SH, et al. Free medial plantar artery perforator flaps for the resurfacing of thumb defects. Ann Plast Surg 2010;65:535-40.

2. Wong CH, Teoh LC, Lee JY, et al. Free digital artery flap: an ideal flap for large finger defects in situations where local flaps are precluded. Ann Plast Surg 2008;60:254-9.

3. Xiao C, Bao Q, Wang T, et al. Clinical application and outcome of the free ulnar artery perforator flap for softtissue reconstruction of fingers in five patients. Plast Reconstr Surg 2013;131:132e-133e.

4. Shen XQ, Shen H, Xu JH, et al. Color Doppler imaging of an ulnar artery perforator forearm flap for resurfacing finger defects. Ann Plast Surg 2014;73:43-5.

5. Gao W, Yan H, Li Z, et al. The free dorsoradial forearm perforator flap anatomical study and clinical application in finger reconstruction. Ann Plast Surg 2011;66:53-8.

6. Inada Y, Tamai S, Kawanishi K, et al. Free dorsoulnar perforator flap transfers for the reconstruction of severely injured digits. Plast Reconstr Surg 2004;114:411-20.

7. Cavadas PC, Sanz-Giménez-Rico JR, Gutierrez-de la Cámara A, et al. The medial sural artery perforator free flap. Plast Reconstr Surg 2001;108:1609-15.

8. Wang X, Mei J, Pan JD, et al. Reconstruction of distal limb defects with the free medial sural artery perforator flap. Plast Reconstr Surg 2013;131:95-105.

9. Kao HK, Chang KP, Chen YA, et al. Anatomical basis and versatile application of the free medial sural artery perforator flap for head and neck reconstruction. Plast Reconstr Surg 2010;125:1135-45.

10. Kao HK, Chang KP, Wei FC, et al. Comparison of the medial sural artery perforator flap with the radial forearm flap for head and neck reconstructions. Plast Reconstr Surg 2009;124:1125-32.

11. Kim HH, Jeong JH, Seul JH, et al. New design and identification of the medial sural perforator flap: an anatomical study and its clinical applications. Plast Reconstr Surg 2006;117:1609-18.

12. Xie XT, Chai YM. Medial sural artery perforator flap. Ann Plast Surg 2012;68:105-10.

13. Chen SL, Chuang CJ, Chou TD, et al. Free medial sural artery perforator flap for ankle and foot reconstruction. Ann Plast Surg 2005;54:39-43.

14. Kim ES, Hwang JH, Kim KS, et al. Plantar reconstruction using the medial sural artery perforator free flap. Ann Plast Surg 2009;62:679-84.

15. Thione A, Valdatta L, Buoro M, et al. The medial sural artery perforators: anatomic basis for a surgical plan. Ann Plast Surg 2004;53:250-5.

16. Suri MP, Friji MT, Ahmad QG, et al. Utility of proximally based sural artery flap for lower thigh and knee defects. Ann Plast Surg 2010;64:462-5.

17. Park G, Kim H. Treatment of chronic osteomyelitis using the medial sural perforator flap. J Plast Reconstr Aesthet Surg 2010;63:153-9.

18. Okamoto H, Sekiya I, Mizutani J, et al. Anatomical basis of the medial sural artery perforator flap in Asians. Scand J Plast Reconstr Surg Hand Surg 2007;41:125-9.

(English Language Editor: J. Jones)

Cite this article as: Huang $\mathrm{X}, \mathrm{Xu} \mathrm{J}$, Yang H, Shi H. Reconstruction of thumb defects with medial sural artery perforator flap: case series. Ann Transl Med 2021;9(8):658. doi: 10.21037/atm-21-526 